\title{
A Design for Addressing Multiple Ecosystem Services in Forest Management Planning
}

\author{
Emin Zeki Baskent ${ }^{1,2, * \mathbb{C}}$, José Guilherme Borges ${ }^{3}{ }^{(}$, Jan Kašpar ${ }^{2}$ and Meryem Tahri ${ }^{2}(\mathbb{D}$ \\ 1 Former Professor of Faculty of Forestry, Karadeniz Technical University, 61080 Trabzon, Turkey \\ 2 Department of Forest Management, Faculty of Forestry and Wood Sciences, Czech University of Life Sciences \\ Prague, Kamycka 129, 16500 Prague, Czech Republic; kasparj@fld.czu.cz (J.K.); tahri@fld.czu.cz (M.T.) \\ 3 Forest Research Centre, School of Agriculture, University of Lisbon, 1349-017 Lisbon, Portugal; \\ joseborges@isa.ulisboa.pt \\ * Correspondence: eminzekibaskent@gmail.com
}

Received: 17 August 2020; Accepted: 16 October 2020; Published: 19 October 2020

\begin{abstract}
Forest policy and decision-makers are challenged by the need to balance the increasing demand for multiple ecosystem services while addressing the impacts of natural disturbances (e.g., wildfires, droughts, wind, insect attacks) and global change scenarios (e.g., climate change) on its potential supply. This challenge motivates the development of a framework for incorporating concerns with a wide range of ecosystem services in multiple criteria management planning contexts. Thus, the paper focused on both the analysis of the current state-of-the art research in forest management planning and the development of a conceptual framework to accommodate various components in a forest management process. On the basis of a thorough recent classification of forest management planning problems and the state-of-the-art research, we defined the key dimensions of the framework and the process. The emphasis was on helping to identify how concerns with a wide range of ecosystem services may be analyzed and better understood by forest ecosystem management planning. This research discusses the potential of contemporary management planning approaches to address multiple forest ecosystem services. It highlights the need for a multi-level perspective and appropriate spatial resolution to integrate multiple ecosystem services. It discusses the importance of methods and tools that may help support stakeholders' involvement and public participation in hierarchical planning processes. The research addresses the need of methods and tools that may encapsulate the ecological, economic, and social complexity of forest ecosystem management to provide an efficient plan, information about tradeoffs between ecosystem services, and the sensitivity of the plan to uncertain parameters (e.g., prices, climate change) on time.
\end{abstract}

Keywords: ecosystem services; multiple-criteria methods; decision support system; forest management planning; participation

\section{Introduction}

Historically, forest management planning has focused primarily on the productive functions of forest ecosystems, mostly overlooking other forest ecosystem values or services. As such, management options such as harvesting, regeneration, and afforestation have often been scheduled in order to address timber and revenue flow concerns. Forest management planning traditionally refers to the process of creating a specific plan that governs optimal resource allocation on the basis of forecasts of future forest production and the planned implementation of a set of management interventions. However, over the last two decades, demographic and socio-economic trends have configured a new forest management planning context characterized by concerns with providing a broader range of multiple ecosystem services. The evolvement of the forest management planning concept from solo 
wood production and economic goals towards multiple uses with a multi-criteria decision-making approach has motivated research to harmonize the ecological, economic, and socio-cultural values of forest ecosystems on a sustainable basis [1]. Furthermore, spatial components of forest planning processes have also increased dramatically in the last decade, as management goals accounting for the spatial configuration of management actions have become increasingly important [2]. Currently, forest managers and practitioners are challenged by developing and implementing plans to reduce the risk of many biotic or abiotic disturbances, increase ecosystem resilience and water yield, protect soil erosion and biodiversity, improve tree growth and vigor, and provide landscape aesthetics and recreational services.

In order to address these challenges, various decision-making tools have been developed to overcome the increasing complexity of the forest management planning problem, namely, the need to examine trade-offs among multiple political, economic, ecological, and socio-cultural dimensions while guaranteeing efficiency as well as acceptability of forest management plans. The forestry literature reports the development and application of several approaches to address the provision of multiple ecosystem services by forest management plans [3-9]. Some authors have focused on reviewing approaches to address a specific ecosystem service; for example, Ezquerro et al. [10] developed a comprehensive review of techniques used to address biodiversity concerns. Other authors focused on evaluating advanced methods that might address a wider range of ecosystem services. For example, Baskent [11], Shan et al. [12], and Llorente et al. [13] examined management approaches to accommodate spatial aspects of forest planning while Bettinger and Chung [2] reviewed the application of multiple objective optimization methods in forest management. The potential of multiple criteria methods to support the development and social acceptability of forest management plans, targeting several ecosystem services, has also been addressed by several authors [5,6,9,14-16]. Information, knowledge, and envision regarding the impact of alternative forest management interventions on management objectives and ecosystem services is hardly ever perfect. This has prompted the research of management science approaches that may provide additional insights on management planning [8,9].

Nevertheless, to our knowledge, no structured framework has been presented that may guide forest managers and practitioners to develop plans that may target the provision of several ecosystem services. The structured framework describes a feasible, strategic approach to link understanding and decision-making with the appropriate dimensions and context by describing organizational structures and processes to support multiple-use forest management, integrating the technical and social aspects of forest management such as modeling, and linking learning to forest management planning and implementation. In this research, we present a structured framework that addresses the planning processes targeting the provision of multiple ecosystem services as well as the features of tools needed to address them. We build from a survey that characterizes the experience and expertise available worldwide to plan for multiple ecosystem services [8]. We consider the development and implementation of conceptual approaches to multiple ecosystem service management planning and the use of decision support systems (DSS) to automate these approaches and provide further information about trade-offs between planning criteria. For clarity, firstly, we outline the framework structure, namely, its compositional, spatial, temporal, and decision-making context dimensions. Secondly, we examine how the framework components relate to stages of the ecosystem management planning process as well as to policy and governance. Thirdly, we discuss the role of decision systems as a key framework of technological enablers.

\section{The Framework}

The development of our forest management planning framework builds from a recent survey of models, methods, and tools to support forest management planning [8]. This survey classified forest management planning problems according to a set of dimensions. It highlighted the spatial scale values, the spatial context, the compositional context, the decision-making context, and the temporal aspects that are best suited to address the provision of multiple ecosystem services. Specifically, 
it emphasized the importance of acknowledging the spatial and temporal interactions of decisions made in neighboring stands (or other areal units). The provision of several ecosystem services (e.g., water, biodiversity) depends on the spatial conditions generated by the spatial layout of management options. It emphasized further the importance of extending the planning horizons to acknowledge the temporal interactions of management options and address ecosystem service sustainability concerns.

Therefore, the framework is characterized by the compositional context including broad and finer level classification of forests (Figure 1). This context contributes to defining the range of ecosystem services that the forest may provide, i.e., the goods and services dimension of forest management problems [8]. The forest inventory may focus on a coarse level identification of forest types into vegetation associations, habitat types, and age classes depending on management objectives. The inventory can also identify the landscape into much smaller details of characterization, such as stands or cells. Likewise, the framework is also characterized by the spatial scale extending from a broad level consideration of forest or landscape-level to a finer level consideration of stands. It underlines the need to develop and regularly update a spatial database for storing and using spatial data (maps and attribute data). The forested landscape must be classified into stands, e.g., homogeneous land units where management options may be implemented, providing a uniform (per hectare) ecosystem service outcome. Characterization of forests into the finer units, such as stands, affects the size and precision of decision variables in developing a better landscape projection model. Moreover, on-the-ground identification and effective implementation of management prescriptions heavily depend on the accuracy of forest characterization into the stands. Moreover, stands may be grouped into higher level units (such as stand type, vegetation type, or habitat type), where a specific forest value may dominate, mostly because of static attributes/variables such as topography (i.e., slope, aspect, elevation) or legislative mandate such as protected areas for biodiversity conservation or some other political necessities. Alternatively, land allocation and stand management scheduling may be integrated rather than developed sequentially.

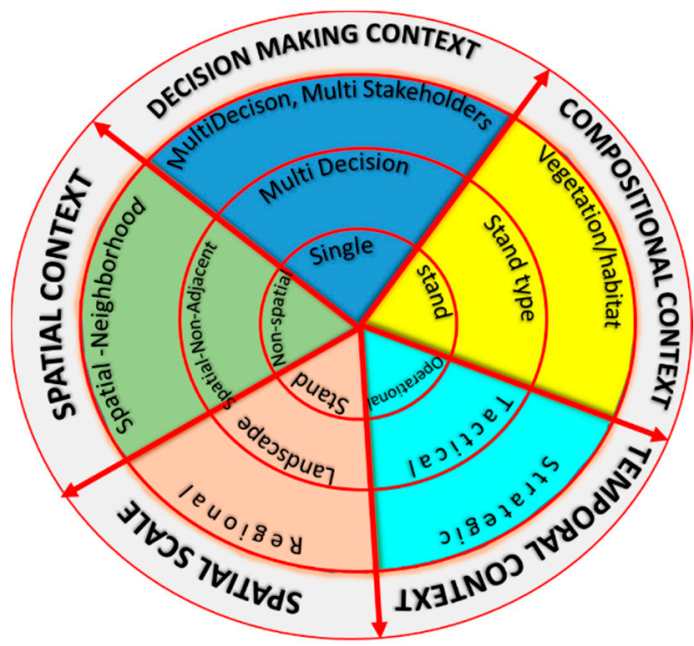

Figure 1. A contextual organization of basic components of the framework for addressing multiple ecosystem services in forest management planning.

Furthermore, the spatial context of management actions is a prevailing consideration within the framework. Among the factors that encourage spatial forest planning are the regulations and voluntary guidelines on harvest units and wildlife habitat patterns. Factors that complicate its adoption include technological, financial, and personnel hurdles as well as insufficient data [17]. Nevertheless, international conventions such as biodiversity conservation and sustainable forest management (SFM) initiatives require certain spatial considerations in planning such as interior areas, harvest unit size, riparian buffers, and patches arrangement. These policies acknowledge that some ecosystem services such as water production, wildlife conservation, and soil protection depend on the spatial arrangement 
of management options. For example, the spatial juxtaposition (i.e., neighborhood or adjacency) of management interventions affects parameters such as core area, a proxy indicator for certain target species in wildlife management, calling for a need to address the spatial location of management operations. It is important to note that the specific implementation of spatial context (e.g., harvest block size, adjacency delay, habitat configuration) in the framework is scalable and flexible according to the management policies and guidelines of various jurisdictions worldwide.

In fact, characterizing and controlling the spatial configuration, composition, and size of patches (i.e., habitats, forest types, stands and age classes) is a major challenge to address in management planning. Specifically, block size, shape, opening size, and green-up delay of harvesting units or blocks as well as the core area, edge length, size distribution, and connectivity of forest patches are important spatial indicators. Several indicators are used to account for provisioning and sustaining ecosystem services and thus must be considered in the framework. The composition and configuration of forest ecosystems in general (i.e., landscape fragmentation) formed by either any management interventions or natural disturbances help determine the provisional level of ecosystem services. Specifically, any management options such as stand treatments in addition to harvesting, fire management precautions, erosion prevention activities, biodiversity conservation and afforestation requiring operational consideration, and spatial arrangement of stands may well be used for meeting multiple-use objectives. Therefore, addressing the spatial dimensions of any management options in the framework typically requires the use of exact and/or heuristic spatial optimization approaches [11,13,17-24].

The framework is characterized further by the temporal context determined by the long-term strategy to short-term operational dimension (Figure 1). Managing for multiple ecosystem services requires a greater number of approaches, including the riparian treatments, recreation infrastructure, restoration activities, best management practices, timing restrictions, prescribed and managed fire, and a plethora of other options available to forest managers and practitioners. However, the supply of multiple ecosystem services is achieved predominantly through decisions on how to schedule management interventions over time and space, as well as how to harmonize the results of management alternatives with the active involvement of stakeholders. The decision alternatives faced by the forest managers relate mainly to the application method, level, timing, and space of various management interventions or options. The biological processes involved give particular prominence to medium-to-long-term temporal considerations. Therefore, the framework acknowledges the need to forecast the development of forests over time. Vegetation dynamics models (e.g., forest species growth and yield models) must be used to project each stand in the forested landscape over time. Furthermore, any biotic, abiotic, social, and ecological changes in forest ecosystems need to be projected in forecasting multiple ecosystem services. This is key for the simulation of the landscape structure over time and for the generation of forest resource capability models to solve multi-objective management planning problems [9].

Moreover, when management planning targets multiple ecosystem services, the decision-making context is often characterized by more than one decision-maker and/or other parties with no formal decision-making power and that yet are influenced or may influence the decision (stakeholders) [8]. Thus, the framework is characterized further by a participatory dimension and the need for collaborative planning and consensus building approaches (Figure 1). Decision-makers and stakeholders have to consider a wide range of often conflicting objectives and either specify the desired level of achievement or specify the various goal preferences [25-27]. The forestry literature reports several discrete approaches to address multiple decision-making problems [3,6,26,28-30]. These include various multi-criteria decision support approaches such as analytic hierarchy process (AHP), simple multi-attribute rating technique (SMART), outranking methods, voting theory, and stochastic multicriteria acceptability analysis (SMAA) to help resolve conflicts and improve the efficiency of the planning process. Nevertheless, the number of management alternatives may require continuous approaches [9]. Thus, new decision-making approaches provide additional insights about the resource capability model and the trade-off analysis between ecosystem services and multiple decision-makers and stakeholders [8,9,31-33]. 
Addressing the decision-making context framework's dimension may require further analysis of the interests and the power of actors involved. The actor-centered power approach developed by Krott et al. [34] allows one to evaluate the level of power resources for each actor type and each interest in ecosystem services [35]. This may be influential in promoting the engagement of decision-makers and stakeholders in the planning process and facilitating the development of socially acceptable plans with specific targets for multiple ecosystem services. Having an ultimate authority with all powers and benefits in managing natural assets endangers creativity, sharing, and accountability in the planning process. Thus, a strong liaison and coordination between the state institutions and civilian stakeholders is necessary, the effective use of technological decision-making tools is critically important for effective communication among the stakeholders, and willingness as well as enthusiasm of authorities is essential to develop plans targeting the provision of multiple ecosystem services $[1,36]$. Using quantitative methods, fostering discussion qualities, securing representation, and increasing motivation for cooperation are also necessary components of the structured participation. As more ecosystem services are demanded by the involvement of multiple stakeholders, new technologies and decision-making tools are developed, scientific understanding of forest dynamics is improved, practitioners are equipped with the necessary wherewithal, and policy makers are convinced, and thus the framework will have a better ground to be implemented in practicality. The important caveat is that the framework is designed on the basis of current understanding and future vision on forest management planning. Nevertheless, the abovementioned initiatives help boost the smooth transformation of the concept towards the ideal framework on the basis of continuous improvement over time.

\section{Implementing the Framework in Ecosystem Management Planning}

On the basis of identifying primary forest management planning contemporary processes, a conceptual flow to encapsulate and harness the framework components may be developed for the sustainable provision of multiple ecosystem services (Figure 2). This conceptual flow starts with forest ecosystem characterization through ecosystem inventory and gathering data from other sources to establish the spatial database (i.e., graphical, attribute, and other informal data). Contents, coverage, accuracy, and precision of the data are relevant to identifying and quantifying the ecosystem services. On the basis of such comprehensive data, planning targets for ecosystem services addressed by national and international conventions may be formulated to reflect the vision, goals, and planning entity strategies. Decision-making tools, tailored to address relevant temporal and spatial scales, spatial context, and participatory concerns, are used to project future development of forest conditions on the basis of the target and the management strategies. These tools help provide information about trade-offs between ecosystem services, appropriate management schedules, and its sensitivity to uncertain parameters (e.g., climate change). Trade-offs generated from the scenario analysis using DSS should be shared with stakeholders through an iterative process that acknowledges the qualitative impacts and feedback required to perform participatory planning. The main strategy promises the provision of the appropriate mix of multiples ecosystem services, conforming to the sustainable use of resources, enhancing land productivity, and accounting for climate change effects. The relevant schedule is determined on a temporal hierarchy encompassing long-term projection to short-term details of operations with or without multiple stakeholders' involvement. The output of the plan is the proper balance between the sustainable use and conservation of forest ecosystem services in accordance with both national and international regulations and policies. Using qualitative data and intuition of decision-makers and stakeholders as part of knowledge management to grasp the real essence of the planning process is important. In fact, forest management planning is not a linear process; it is rather an adaptive learning process where the output (decisions and assumptions) is monitored, assessed, and revised regularly, leading to revisiting and refining the plan for effective implementation on the ground. 


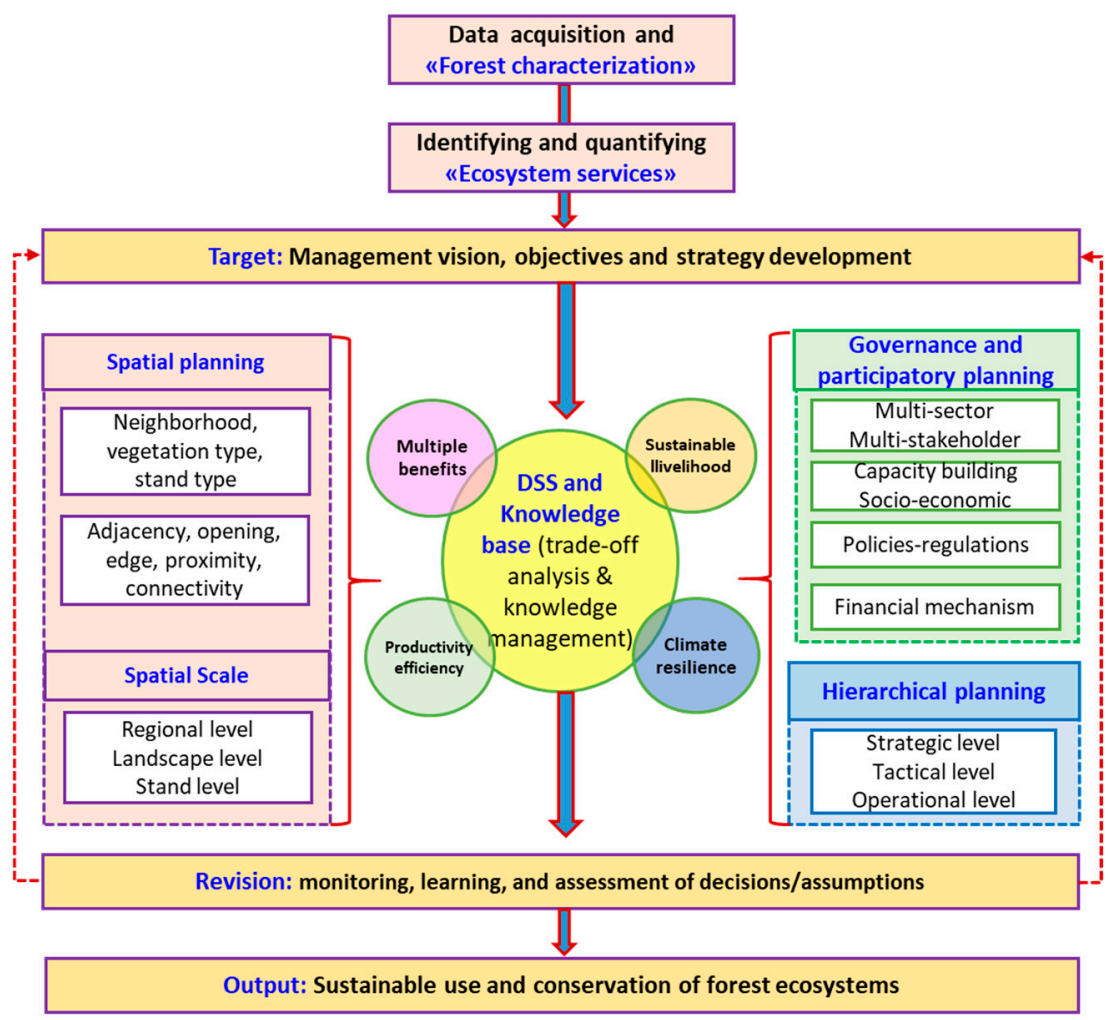

Figure 2. The conceptual framework components indicating the organization and connections to ecosystem planning processes.

The flow displays the comprehensive interconnection of components and indicates the stepwise process of management planning. The correspondence between the framework components and the ecosystem management planning processes may be summarized as follows:

- Forest characterization and ecosystem services: Compositional context, structural characteristics of forest ecosystems, and range of goods and services they may provide.

- Hierarchical planning: Temporal scale.

- Spatial planning: Spatial scale and context.

- Participatory planning: Decision-making context with actors, regulations, and policies.

- Decision support and knowledge-based systems: Decision support to manage the planning processes.

- Forest governance: Regulatory and policy instruments to maneuver the planning.

\subsection{Forest Characterization and Ecosystem Services}

The planning process starts with the inventory and classification of forest landscape into various stand types and use categories on the basis of defined guidelines. Both compositional and configurational characteristics of forest ecosystems are identified to establish a comprehensive forest inventory with a well-developed inventory method. The compositional features include species mix, development stages, crown closure, density, and stoking levels, while the spatial configuration refers to the size, shape, and spatial distribution of stands. The scale or resolution, types, and characteristics of stands help identify the inventory data's coverage and quality. The scale ranges from stand-based information to a broader classification of forest types such as hardwood, softwood, or age classes. It is crucial to establish a detailed representation of forest landscape in an inventory database for effective decision-making and implementation. Given the forest ecosystem characterization with stands, potential forest use categories may then be pre-determined on the basis of a set of criteria and indicators using a participatory approach. Each category represents and serves a specific set of forest ecosystem services for which the area is potentially aimed to be managed under particular 
management regimes with certain silvicultural prescriptions. Thus, sound characterization of land use categories and determination of the value-category relationships are highly influential in setting management objectives and conservation targets and developing appropriate prescriptions accordingly for effective decision-making process.

At the outset, the classification accommodates ecological, economic, and socio-cultural features of forests into a coherent framework, providing priority to the specially designated areas such as statutory areas and legally binding, technically limiting, and socially conflicting regions. The quality of ecosystem characterization is associated with the legislative mandate, available resources, technical requirements, and societal expectations in addition to the recency, accuracy, consistency, and the details of the data. Here, developing a set of criteria and indicators is critical for a scientifically vigorous, socially acceptable, and operationally feasible landscape classification. The effectiveness of landscape characterization depends highly on transparent designation criteria, objective-oriented management measures, structured participation, and efficient legal and financial instruments.

Ecosystem goods and services (shortly called services) are categorized mainly into ecological, economic, and socio-cultural functions; values; or benefits according to the SFM initiative. They are the three fundamental pillars of the initiative around which forest management planning is tailored to satisfy society's needs. They range from tangible products such as provisioning services of wood and freshwater production to intangible products such as cultural services of recreation and aesthetics [37]. Thus, ecosystem services are identified and classified as provisioning, regulating, cultural, and supporting services according to the classification concept and typology [37-39]. However the ecosystem services are categorized and adapted, the critical point is the characterization (i.e., identification, quantification, and valuation) of ecosystem services (ES) to be well integrated into the forest management planning process $[37,40]$. In order to integrate ES in management planning and analyze the tradeoffs, they have to be recognized with a developed set of criteria and be quantified on the basis of certain parameters. While there are some approaches in quantifying ecosystem services, it is sometimes quite cumbersome to quantify particularly intangible ecosystem services (i.e., supporting and cultural services) such as biodiversity and recreation with the similar quantitative rigor as in tangible ecosystem services (i.e., provisioning services such as wood production). In fact, both composition and spatial configuration of ecosystem services such as richness, abundance, evenness, and habitat distribution at various temporal and spatial scales need to be identified and quantified, complicating the characterization process. In order to circumvent the problem, however, some proxy measures are generally used in practice to characterize such ecosystem services [37]. For example, Edward et al. [41] developed concepts, dimensions, attributes, and indicators to determine the aesthetic/recreational value on the landscape level. Similarly, Eriksson and Hammer [42] provided an approach to characterize habitat for biodiversity using species composition, deadwood, and tree sizes, as well as spatial fragmentation, including shape, juxtaposition, and the connectivity of habitats in the landscape. Regardless, identifying as well as understanding the different natures of ecosystem services is crucial during the integration and interpretation of multiple ecosystem services in a holistic management process. A conceptual framework was well developed and explained to integrate ecosystem services into the multiple-use forest management planning process by Baskent [36].

\subsection{Hierarchical Planning}

Forest ecosystems are naturally developed and organized in a hierarchical structure with larger units at a broader scale (i.e., age class distribution, forest type classification) encapsulating the smaller units (i.e., vegetation types, stands, group of trees) at a finer scale. Similarly, decision problems at each organizational or classification level in forest management planning differ in time horizon, management level, spatial coverage, source and detail of information, and the risk and uncertainty associated with the outcome [43]. Managing all forest ecosystem features in a holistic approach may need to address issues at various organizational scales in a management hierarchy. Thus, the decision-making 
process involved in planning often encompasses a management hierarchy, ranging from strategic level decisions to operational level decisions.

The strategic level decisions related to the development of broad level policies of land use management. They focus on long-term analysis of resource availability to optimize the enterprise's performance over time. Long-term plans are developed for multiple periods to assess the long-term availability of ecosystem services. They have to address higher levels of risk and uncertainty that result from its temporal dimension. Specifically, long-term resource availability, climate change effects, broad-level policy formulations, and forest composition development with limited spatial consideration are tested and determined at a strategic level. Thus, a broader level allocation of the landscape to various forest uses with certain targets and objectives is determined at this level. The output of the upper level models often becomes an appropriate constraint for the lower-level models due to hierarchical encapsulation of planning features.

Intermediate or tactical level decisions address the most effective use of the resources available to the enterprise in the medium term. Tactical plans try to guarantee long-term wood supply with the highest income level. In some cases, the distribution of product types relative to the appropriate assortment categories such as sawlog, veneer, pulp, paper, and firewood is determined at this level rather than at the strategic level. Moreover, the association of silvicultural regimes (e.g., prescriptions) to the land units that result from landscape classification takes into account spatial information that typically is ignored by strategic models. Thus, the spatial details of the implementation of silvicultural interventions as well as of the road network are often taken into consideration at this level to decide where and the products should flow. Furthermore, the available workforce and mechanization, enterprise production plan, and seasonal changes in the process of marketing products may also be included at this level. Briefly, the tactical level plans simply involve detailed scheduling of silvicultural interventions and other non-harvest-related activities on a periodical basis. However, with the advancement of technology, tactical-level decisions are often combined into the strategic level decisions as large datasets and various management scenarios can be processed and analyzed with various decision-making tools.

Operational level decisions consist of scheduling year-round (i.e., monthly, weekly, or even daily) silvicultural and transportation activities to make the system function. The operational plans identify the level and the specific time (year, month, or week) of harvesting/tending stands, silvicultural plan, forest workforce, logging and transportation means, wood procurement and assortment, and non-harvest related activities. Detailed schedules at the operational level are prepared for all the other management actions needed to meet the objectives for multiple ecosystem services. In short, the decision-making process at an operational level is quite specific, cost-effective, and detailed for a particular industry or institution, with less risk and uncertainty.

Each model is aimed at a specific level of management and goals and objectives. Indeed, decisions taken at one hierarchical level act as targets or constraints on the next lower level decisions. Information feedforward and feedback through the hierarchical plans enable the organizations to function effectively and establish the basis for the realization of adaptive management of forest ecosystems [43-45]. Such hierarchical planning comprehensively covers various levels of information, decisions, and requirements of forest management planning so that the hierarchical nature of forest landscape can best be represented at various scales.

\subsection{Spatial Planning}

Spatial planning principally refers to the geographic arrangements of both patches such as forest types, stands and habitats, and management intervention units such as harvest blocks across a landscape $[11,17,21,46-48]$. Typically, it is associated with tactical and operational planning levels. Nevertheless, spatial planning features may also be considered over longer planning horizons. Moreover, this is the process that addresses the spatial scale of the management planning problem, namely, whether its focus is on the stand, landscape, or regional scales. Spatial planning accommodates quantitative decision-making techniques to incorporate both ecosystem goods and services with spatial 
features into a forest management plan easily applicable on the ground [17,49]. It is further addressed by planning methods that target the solution of logistics and transportation problems [50,51]. Forest management planning policies and regulations in different jurisdictions require certain patterns of treatment units and remaining habitats for either economic of ecological necessities. For example, the economics of forest operations calls for appropriate cluster of all management interventions on spatial locations to minimize the total costs. Both the spatial arrangement of forest units and the scheduling of all management activities across all forest units are of great challenge here. Wildlife management necessitates un-fragmented landscape, focusing on the certain size, adjacency, shape and configuration, or arrangement of both harvesting units and habitat patches across a forest landscape [24,52]. Due to the combinatorial nature of the spatial problem, decision methods used in forest planning have often resorted to heuristic techniques such as simulated annealing, tabu search, genetic algorithm, and cellular automata [1,12,19,53-58]. These techniques may use either an area-based or unit-based restriction model to control the size and adjacency of harvesting areas or units $[20,55,59,60]$. The successful use of these techniques depends highly on the architectural design of the spatial model. In the case of heuristics, it is quite sensitive to the parameters used within the model. For example, the quality of the solution is sensitive to the existence of various optional moves in tabu search $[53,60]$ and cooling schedules in simulated annealing [11]. Since they are inexact techniques, the advantages of various techniques can be effectively combined to develop hybrid models to generate better solutions [60]. However, there are certain areas to improve the efficiency of metaheuristics in forest planning. These include hybridization with exact models, process improvements, reversion strategies, destruction and reconstruction strategies, intelligent or dynamic parameterization approaches, intelligent termination or transitioning methods, and seeding strategies [58]. Nevertheless, new model formulations have demonstrated the potential of using exact techniques to represent and solve spatial planning problems [20,22,61,62].

Indeed, spatial planning focuses on management operations across all programs and landscapes including both harvesting and non-harvesting actions. Aside from harvest scheduling and accessibility, fire, pest, soil, and watershed management require certain spatial features or have additional essential aspects that call for the spatial arrangement of management operations on the ground. For example, spatial juxtaposition of various stand types such as hardwood and softwood stands and topography are crucial elements for fire prevention and effective fuel management [31,63]. Specifically, Marques et al. [31] developed a posteriori multiple criteria decision-making (MCDM) preference modeling approach using wildfire risk criteria derived from stand-level wildfire occurrence and damage models as well as from the characteristics of neighboring stands influencing wildfire probability and spread. Stand geometry (e.g., shape and size) and topology (e.g., spatial context) are used with geographic information systems (GIS) to represent fire resistance and better address wildfire spread concerns. Similarly, Moreira et al. [63] showed that fire spread rate is facilitated by landscape heterogeneity defined by spatial arrangement of fuel types and topography. Thus, the spatial pattern of fire ignition and spread across landscapes is affected by fire proneness, both characterized by GIS. Furthermore, a GIS-based AHP multi-criteria spatial analysis method was applied to integrate and prioritize production and protection functions of forests [64] and to determine cartography of the potential fire risk areas and phytosanitary risk maps [65]. Similarly, Eskandari [66] identified locations for fire ignitions on the basis of fire risk goal as well as the topographic, biologic, climatic, and human sub-criteria parameters used to model the fire risk with fuzzy membership AHP and GIS. Goleiji et al. [67] developed an analytic network process (ANP)-based fire model with 16 criteria to provide a map of potential fire risk zones using DELPHI-WLC and GIS with high model efficiency. Most authors discovered that their mapping results were in concordance with the actual fire occurrences.

Rainfall-runoff models require identification of geographic arrangement of vegetation cover and topography of a watershed [68]. Integration of soil erosion into management planning effectively requires handling of "maximum intervention area" constraints calculated for each stand on the basis of the topographic features and hydrological connectivity (i.e., water flow and slope length 
factor) [69]. Other ecosystem services such as air quality, pollination, water production, and wildfire prevention may also have a certain level of spatial indications that should be considered by spatial planning. Indeed, global conventions on conservation and management of natural resources require certain spatial considerations in planning. These include creating of core areas, limits in harvest unit size, maintenance of riparian buffers, and conservation of certain habitats with spatial configuration. Moreover, connectivity among forest patches is another important spatial feature to be considered in spatial planning [62]. In brief, recognizing the specific geographic location of management interventions can help planners and practitioners better realize the provisions of various ecosystem services requiring spatial restrictions, thus allowing them to make appropriate decisions [11,70].

\subsection{Participatory Planning}

Decision-making in forest management planning with multiple objectives is more challenging than ever as decisions have to be made according to economic, ecological, and social perspectives. Such planning process often involves various stakeholders, experts, or decision-makers and the forest owners, all of whom may have to use tools to address problems that are characterized by multiple and often conflicting objectives, creating a complex decision-making environment. To ease and overcome management planning complexity with multiple objectives, both technological tools and participatory approaches need to be applied. Participation is generally employed in (i) classifying land base for various forest use categories, (ii) setting up management objectives and listing ecosystem services to provide (iii) help in evaluating trade-offs between these services under different management scenarios and (iv) selecting to the plan to implement. Thus, the role or the concept behind the framework indicates that participation happens throughout the management process. The required input source of information in structured participation would primarily be the institutional capacity inventory, including the technical and professional human resources available in a given institution. Furthermore, participatory planning acknowledges and respects traditional ecological knowledge and other qualitative inputs during the discussion and the trade-off analysis to improve the decision-making process.

Structured participation of stakeholders in natural resource management is a constant process requiring a continual dialogue throughout the management process. Developing trust and having informed participants needs to be initiated long before engaging in a strategic forest management planning efforts. Traditional participation has some pitfalls. Some participants may attend the meetings and yet fail to commit to take roles and responsibilities. They may also have insufficient knowledge about management techniques and legal rights, while meetings are sporadically held and irregular. On the other hand, structured participation recognizes the adaptive nature of the management process and can be implemented throughout the planning process. Preferences and knowledge are shared among the participants. A structured participation process helps translate forest policies and regulations into the actions in the field and contributes to informed decisions (Figure 3).

The first stage of structured participation is the identification of stakeholders [25]. Actors include local and county agencies, forest industries and associations, scientists, local politicians, and several other local forest-related organizations. The second stage is to create awareness among the stakeholders on the status of forest ecosystems. The contribution of natural resources to the quality of human life is highlighted for the actors to appreciate the significance of sustainable use of ecosystem services. Information is generated and a knowledge base is built to initiate informed discussions for better decision-making. In the third stage, various opinions arising on the issues are discussed and the decisions result from a negotiation process. Ecological attributes, quality of life, global warming, and economic considerations are some contemporary issues for discussion. Using quantitative and qualitative methods in the participatory situation, fostering discussion qualities and securing representation, and increasing motivation for participation are necessary factors for the participatory process of management planning. The ownership history, the present and future management goals, ecosystem services produced, opinion on forest management activities, forest management tradition, forest legislation, actors in the forest landscape, local conflicts, cooperation, and networking are 
important factors to be considered in the participatory process. One of the most important yet neglected stages of the participatory process is sharing the rights and responsibilities among the key stakeholders towards the co-management or governance of ecosystems. Roles or rights and responsibilities of the stakeholders are to be clearly defined so that the selection of ecosystem service target levels as well as the plan may be provided transparently. It would be quite difficult to see the positive effect of participation in ecosystem service management unless this stage is performed. Finally, those who hold the rights to manage the ecosystem services need to be accountable for the results of executing forest management activities to the public to build trust among the public.

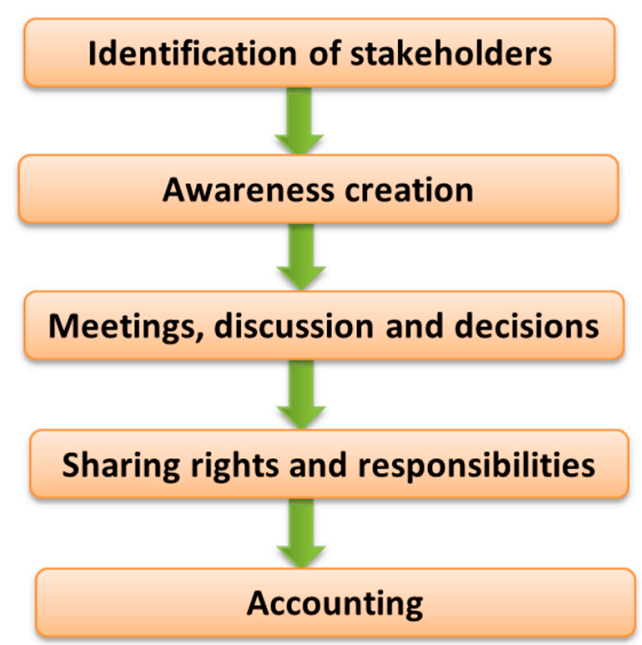

Figure 3. A simple process of structured participation.

Undoubtedly, some forest values may be in conflict with others due to the ecological-economic (e.g., production and conservation functions) and socio-political (e.g., strong coercion, incentives, and dominant information as power resources of stakeholders involved) contexts [34,35,71]. Participatory planning should provide opportunities to equally treat stakeholders and not to marginalize any community or interested party that would be impacted by the forest management plan. The actor-centered power approach developed by Krott et al. [34] allows one to evaluate the level of power resources for each actor type and each interest in multiple forest values. Such an approach can also help identify the conflicts that need to be dealt with the management planning process [35].

There are various approaches to address participation in forest management planning. They include multi-attribute and multiple criteria decision-making techniques such AHP, ANP, technique for order preference by similarity to an ideal solution (TOPSIS), VIKOR (Vlse Kriterijumska Optimizacija Kompromisno Resenj) method, fuzzy logic, goal programming, and Pareto frontier methods. They help to elicit stakeholders' and decision-maker's preferences [5,25,27,72]. They are utilized further to quantify the relative values of ecosystem services; incorporate stakeholder preferences in economic, environmental, and social values; and increase the transparency and the credibility of the management planning process. They have been proven to be useful tools for analyzing stakeholders' preferences, negotiating ecosystem service target levels, and helping build consensus, thus contributing to improving the decision-making process. Moreover, they also contribute to the effectiveness of the communication among the stakeholders and provide information to internalize the sustainable management and governance of ecosystem services as common assets [36,73]. Furthermore, setting up legal, institutional, and policy frameworks to create an enabling environment for planning involves strengthening institutional capacities as well as collaboration and networking. Participatory planning brings together all interest groups and planners for co-management of a forest landscape. It also helps create strong coordination, collaboration, and communication among multiple stakeholders for effective execution of the planning process. 


\subsection{Decision Support and Knowledge-Based Systems}

The development of the forest ecosystem management planning processes (Figure 2) requires the use of information and communication technology (ICT) so that all components of the framework (Figure 1) may be adequately addressed. The characterization of the forest and ecosystem services relies on remote sensing as well as on information systems and databases to automate data acquisition and management. Moreover, the efficiency and effectiveness of hierarchical, spatial, and participatory planning depend on the automation of the simulation of the future development of ecosystems and the corresponding resource capability models that detail how each management alternative may contribute to each ecosystem service provision. They depend further on the automation of the generation of the decision space and the selection of plan proposals. The former brings together resource capability and policy models while the latter encapsulates techniques to search for the plan that approximates most of the decision-makers' objectives. However, modeling always has some assumptions and uncertainty that needs to be interpreted cautiously. Moreover, it is not straightforward as to how to quantify and model some ecosystem services, requiring more of a qualitative characterization of such ecosystem services.

Reynolds et al. [74] listed the drivers behind the adoption of ICT and the growth of ICT innovations in forest management, namely, the advances in scientific understanding of forest systems, public pressure for involvement in resource management decisions, and organizational needs for enhanced competitiveness. These ICT tools are typically combined within modular structures such as DSS and knowledge-based systems (KBS). DSS encompasses four main modules. The first consists of the database management system, which addresses the compositional and ecosystem services context of our framework. The second consists of a model base that encapsulates the vegetation dynamics model as well as the ecosystem services models [74-79]. It is used to generate the resource capability models needed to address the temporal context as well as the spatial context and spatial scale components of our framework. The third consists of a methods base that encapsulates decision-making methods, e.g., as linear programming, mixed integer programming $[20,22,23]$, goal programming $[5,80]$, stochastic programming [80-82], Pareto frontier methods [9,31,83], and heuristic techniques $[1,4,18,19,53,55-58]$. The methods base integrates the resource capability model with the policy model to reflect the ecosystem services targets by the decision-makers. It thus addresses the decision-making context of our framework. The fourth consists of the graphical user interface developed so that decision-makers or decision analysts may interact with the data, the models, and the methods. Typical KBS include three main modules where the first consists of an interface to capture knowledge from experts, the second consists of the knowledge base and its logical models, and the third is the explanation interface that builds from logical and inference models to provide information to the decision-maker [84]. These three modules may help address any of our framework components. As pointed out by Reynolds et al. [74,85], hybrid systems that combine functionalities of KBS and DSS, e.g., by KBS symbolic processing of information provided by DSS modules, may further improve both the efficiency and effectiveness of forest ecosystem management. Furthermore, simulation and scenario analysis, behavior models, agent frameworks, social networks, and multiple criteria methods are additional decision support tools to help analyze and discuss their use to support policy analysis [86]. However, such a global approach with the necessary components is flexible enough and could well be adapted to various jurisdictions across the world depending on their capability and resource capacity.

Reynolds et al. [87] reviewed some of the more important issues in the development of DSS and KBS for forest ecosystem management. The authors included a synopsis of computer-based tools $[85,88-95]$ that highlights how these tools' availability may contribute to address concerns with the provision of ecosystem services. Vacik and Lexer [96] showed further that the design of DSS architectures and the selection of models and methods to encapsulate in its modules have been driven both by forest ecosystem management needs-namely, by the range of ecosystem services to consider, as well as by the availability of decision support technologies. The report of the experience of using DSS worldwide does highlight the pervasiveness of its use to address the provision of ecosystem 
services [8]. Moreover, recent developments show how these computerized tools have been tailored to address the components of our framework and support the corresponding planning processes. For example, Marto et al. [97] report the first application of a system that combines knowledge-based logical modeling and DSS simulation models as well as decision-making methods to help stakeholders select baskets of ecosystem services and the corresponding management plans. Moreover, web-based systems have been presented by Marto el al. [98] and Rammer et al. [99] to facilitate the involvement of stakeholders in planning processes and to address adaptive management, respectively, while Nordström et al. [100] discuss the application of several DSS to address the provision of a wide range of ecosystem services under scenarios of global change.

Socio-economic and environmental trends impact forest ecosystem management settings and are thus key factors for DSS development [101]. Namely, different expectations on future DSS may cause several dilemmas [101]:

- Various user groups require complex forest models, which might lead to overwhelming decision-makers and DSS users.

- Users expect easy-to-use and smart tool-like apps running on their smartphone.

- The demand for meaningful cases of forest DSS is increasing, meaning that more emphasis will have to be put on the way in which information is presented.

- Emphasis may have to be given to consider of the "joy and play" factor in the design to decrease the barrier for the general use of DSS.

DSS architecture approaches [102], with its emphasis on stakeholders' involvement on the development of the tools, may contribute to the usefulness of the DSS [103] and thus address these dilemmas. Another possible future development that could help to dilemmas address them is the use of serious games, i.e., "games that do not have entertainment, enjoyment, or fun as their primary purpose" [104]. Their use for planning and problem-solving has grown exponentially in recent years [105]. Rodela et al. [106] explore further the possibility of using them to support forest ecosystem management planning processes.

\subsection{Forest Governance}

Forest governance involves the policies, processes, and institutions through which decisions are made about the utilization of the land and its resources (ecosystem services), the manner in which those decisions are implemented and enforced, and the way in which competing interests in land are managed [107]. Setting up legal, institutional, and policy frameworks to create an enabling environment for planning involves strengthening institutional capacities as well as collaboration and networking. Governance brings together all interest groups and planners to co-manage a forest landscape and create strong coordination, collaboration, and communication among the stakeholders.

Forest governance is a crucial component of management planning involving the development and enforcement of policies and regulations to execute management plans effectively. Unless the necessary legal basis is established, it would be quite difficult to realize any theoretically sound management planning approach by the owners and the practitioners. Forest policies and regulations are considered important legal instruments for advancing and realizing ecosystem management initiatives [108]. It is crucial to recognize the overlapping rights and responsibilities of institutions in forestry. Thus, a coherent policy document, including rules, regulations, permissions, monitoring, collaborations, and stakeholders' responsibilities, is necessary for implementing an effective management plan [71].

Perverse land-use policies, stringent regulations, inadequately funded government institutions, and a severe lack of enforcement capacity are some examples of cause of failure in implementing forest management plans. Competing land uses, unclear tenure, and limited institutional capacity for effective implementation and enforcement of legal frameworks on forests continue to be significant challenges for forest management. In fact, a lack of rules and their implementation may lead to unsustainable forest resource management; on the other hand, fewer rules and requirements may lead to smarter 
regulation if many rules and bureaucrats impede innovation and adaptive management. Exploring a balance between these two extreme situations is a challenge for forest stakeholders worldwide [108] and may be the ultimate target in developing and enforcing the right policies and regulations for forest ecosystem management. Various decision support tools such as simulation and scenario analysis, behavior models, agent frameworks, social networks, and multiple criteria methods have been used to help analyze and discuss their use to support policy analysis [86].

\section{Discussion}

In this paper, a framework is presented that accommodates various forest management planning components and a flow of planning process in which those components are integrated. On the basis of this framework, we defined five elements-decision-making context, compositional context, temporal context, spatial context, and spatial scale-along a planning process gradient. Decision-making context of today's forest management planning needs to take into account multiple actors with multiple criteria decision analysis in a spatial context considering geographic configurations of stands/habitats and intervention units. Most of the ecosystem services require a certain level of spatial consideration that should be accounted for in the planning at various spatial scales. In addition, accurate stand base forest inventory data are required to represent and characterize landscape with various compositional contexts such as habitat, stand type, and stand, depending on the details of the required information. In terms of temporal context, management planning is a hierarchical planning process covering the strategic decisions to ascertain the long-term availability of ecosystem services as well as the details of stand level decisions to develop an on-the-ground applicable management plan.

A set of contemporary literature, mostly in the form of case studies, has been found to focus on the review of multiple-use forest management planning, particularly models and methods used to address concerns with the provision of ecosystem services in forest management planning [109,110]. The methods and tools covered in this paper were compiled and evaluated with respect to several schools of thought, including the philosophy and visions of forest management planning concepts. For example, Ananda and Herarth [6] reviewed some apparent MCDM and their implications in forestry, emphasizing the proliferation of hybrid methods instead of solo goal programming to maximize the synergy. Nyongesa and Vacik [111] provided a comprehensive methodological approach utilizing MCDM (i.e., AHP) with a set of objectives and criteria to address the complexity of the decision problem in a transparent and understandable way and minimize the information gap between decision-makers at the local and national levels, facilitating the structured participation, proposed in this study, by diverse professionals, experts, and interest groups. Lodin et al. [112] indicated that the achievement of traditional forest management objectives is limited to the projected climate change scenarios using a strategic level planning system combined with a forest owner decision simulator. Benz et al. [113] envisioned the multi-functionality of the forest as a goal of sustainable forest management; multiple actor-based multi-criteria scenario analysis as a requirement for knowledge-based planning; new silvicultural tools to balance ecological, economic, and social expectations adapted to local conditions; and implementation of multi-functionality being a permanent process under dynamic social and environmental conditions. A review by Duncker et al. [110] developed a framework focusing on five management approaches resulting entirely from the intensity of various silvicultural systems spanning from intensive management to a close-to-nature approach. In fact, both Bauhus et al. [114] and Boncina [115] highlighted the importance of a nature-based (close-to-nature) silvicultural system referring to the stand level compositional context (e.g., respecting local site conditions) in integrating nature conservation to ecosystem management framework developed in this study. Another review by Orazio et al. [116] emphasized the landscape level approach to promote sustainably and vulnerability in forest management planning. Baskent [11] reviewed the advancements in multiple-use forest management planning concept, exploring some components of planning, highlighting the need for improved stand projection models to account for climate changes, upgraded functionality of DSS to accommodate various ecosystem services, use of expert knowledge, better communication with the 
stakeholders, and opportunity to analyze trade-offs. For example, rather than using a typical empirical growth and yield model to project stand growth, managers may take advantage of process-based models and climate change-sensitive simulators capable of projecting stand development under both natural and anthropogenic disturbances [117]. While all address various aspects or dimensions of forest management planning, it appears that there is still vagueness in decision criteria that should be refined, and the value judgement should be promoted through innovative approaches that use schematic diagrams with visualization and animation techniques.

Development and transparent use of various analytical tools such as hybrid modeling $[27,60,74,85]$ with additional functionalities to integrate multiple objectives accommodating risks and uncertainties [118] as well as social dimension can address the future modeling challenges in developing a sound management framework. In this work, hybrid modeling refers simply to the combination of various decision-making techniques (particularly exact and inexact ones) in a comprehensive DSS as a consolidated methodology to represent the whole process of forest management planning explored in this study. This study reports on the aspects of the frameworks to characterize forest management in a planning context, indicating how the methods and tools should be tailored to address the components of our framework and support the corresponding planning processes. The framework developed here has been built upon the evolving ideas, visions, and understanding of recent developments in forest management planning and was designed to contribute to the advancement of both understanding of forest dynamics and creating knowledge in the better conceptualization of the management planning framework. Furthermore, this paper can also stimulate a discussion to conceptualize forest management planning by motivating and leading the readers towards a holistic view of planning, just before preparing and implementing a management plan.

Rather than an ordinary literature review, this paper focused on the conceptual aspects highlighting the theoretical underpinnings, the nature of planning problems, the abstract design of management planning, and particularly the methods and tools used in applying the concept. The planning framework and the process developed here can contribute to improving the understanding of the spatially oriented multiple-use forest management planning concept. The paper highlighted the emerging trends in the vision and the use of methods and tools in forest planning. First of all, planning has moved towards characterizing and accommodating multiple ecosystem services to address the increasing and varying needs of society. The challenge identified is the quantitative or qualitative characterization of intangible ecosystem services and integrating them into the planning process for optimal output. A similar conclusion was drawn in the review of Baskent [36], providing a conceptual framework to identify, quantify, and accommodate ecosystem services in forest management planning. The framework developed here highlighted the point to identify and characterize ecosystem services in a common platform with direct or proxy measures before integrating them into a modeling environment to initiate a multiple-use forest management plan.

Spatial planning has become an important component of forest management. Specifically, there is a high trend of tendency concerning the use of spatial planning to address spatial requirements, integrate spatially oriented ecosystem services (e.g., biodiversity conservation and erosion control), and enhance the applicability of the plan on the ground. For example, Llorente et al. [13] recently addressed the spatial facets, including adjacency and harvest area limitations, habitat connectivity, edge impacts, and proximity considerations for restructuring stand shapes and sizes in management planning. They concluded that operation research techniques could help explore the complex combinatorial nature of the situation, integrate multiple objectives over large landscapes, and make trade-off analyses for decision-makers to better understand forest-wide opportunities, suggesting parallel processing to increase the practicality of model applications. Recent studies show a shift towards development and using combinatorial optimization techniques with various exploration and exploitation options, as highlighted by Bettinger and Boston [58], so that the capabilities and effectiveness of heuristic approaches when applied to spatial problems can be enhanced. It appears that algorithmic advancement can definitely accelerate and proliferate the use of heuristics in spatial planning. Thus, a hybrid 
modeling approach accommodating both exact and inexact decision-making techniques may be needed to capture and address the spatial and temporal contexts of forest management planning.

Development and utilization of decision-making tools help motivate individuals to easily identify the untested gaps in management planning and design tests that address important hypotheses. Unless more comprehensive planning options are created and tested virtually (i.e., modeling exercise based on scenario analysis), it is impossible to claim a successful management framework design and its implementing process. Kaya et al. [119] reviewed the use and evolution of optimization-based decision-making tools in forest management planning at various spatial levels. The authors revealed that exact the methods for optimizing systems mainly continue to be used at the forest/landscape level, and at the stand level, optimization seems to now involve the exploration of a variety of analytical methods. They noted that realistic approaches such as non-linear programming, multi-criteria approach, scenario analysis, and mixing optimization (heuristics) are explored to accommodate multiple ecosystem services. In particular, the integration of various ecosystem services with a DSS under the climate change effect has been regarded as a contemporary challenge in ecosystem management [92].

On the basis of the review, developing modular structures of decision tools into a coherent DSS supported by knowledge-based systems (i.e., a hybrid system) helps to address the components of our framework to support the corresponding planning processes to improve the efficiency and effectiveness of forest ecosystem management. In fact, the practicality of forest management models can significantly be enhanced when various hierarchical level models (e.g., strategic and tactical) are integrated within a multi-criteria context [120]. They recommended the extended goal programming (GP) technique to incorporate different spatial issues, including third-level operational level (monthly/weekly) activities. While such an approach is in the embryonic stage, the future challenge is the ability to hybridize a nonlinear GP model with a metaheuristic approach in accommodating stochastic events and multiple ecosystem services with different spatial features at various levels $[9,121]$. However, perception of using models as a panacea (i.e., blind applications of decision techniques) in the case of increasingly complex problems and risks and uncertainties may overwhelm decision-makers using DSS, as noted by Vacik et al. [101] and Ananda and Herarth [6]. It is important to note that DSS may not balance all aspects of the planning framework due mainly to unavailable or insufficient data, too much uncertainty, irregular problems, inadequate technical capacity, and oblivious governance. Learning through practical experiences and trade-off analysis as well as through scenario analysis provides further support to address complex interactions and compromises for managers trying to balance often conflicting ecosystem services. Adaptive management, including some qualitative model-based approaches, may contribute to the learning process and can improve the understanding of these interactions. Intuition, practical observations, role playing, scenario analysis, and continuous learning are all necessary practical aspects of supporting the concept developed here. Realizing the use of models as "a support and game tool" may better implement our framework components and the associated process in the future.

Addressing the complex problems and intractable conflicts (multiple often conflicting objectives) in planning can be an overwhelming challenge. Managing forest ecosystems should recognize the complex and heinous planning problems emerging from intractable and entrenched conflicts over natural resource management and the prioritization of economic and conservation goals [122]. Holistic landscape approaches accommodating various stakeholders across multiple scales, sectors, and knowledge systems has prominence for addressing such complexities [123]. Participatory planning explicitly recognizes the assumptions and enables transparent decision-making while modeling exercises and role-playing games enhance knowledge, capacity, and empathy by exposing actors to diverse perspectives [123].

Current studies on reviewing and developing forest management planning concepts indicated certain improvements in solving contemporary forest problems including characterization and integration of multiple ecosystem services, explicit recognition of spatial facets of planning, certain 
management planning approaches, special silvicultural systems, a combination of operational research techniques (hybrid systems), behavioral models, and trade-off analysis tailored to various facets of forestry problems. Our study analyzed the current achievements and envisages future challenges by providing a comprehensive framework through coverage of planning components and the planning process where these components are integrated into it. In fact, the framework improves upon the contemporary vision of forest management, identifies and characterizes the primary planning components from a broader perspective towards finer details, and assembles them into the planning process. Each component was conceptualized and explored in a way to capture the real essence of the planning process required in developing a functionally operating DSS-based forest management planning model.

One of the important challenges in forest management planning is the accurate abstraction or modeling of stand dynamics. Here, the process-based modeling concept [124-126] may contribute to characterize the dynamics of landscape productivity for multiple ecosystem services with respect to changing natural disturbances and anthropogenic interventions, particularly under various climate change scenarios [127]. In the meantime, however, the process-based models can only be useful if they are able to project the development of different forest types [128], multiple sites [129], and management regimes such as thinning [127,130]. Models are indeed tools to help test hypotheses and help make better or more informed decisions on the basis of simulation of behaviors or specifically forest/stand development under various assumptions and strategies. Their functions are limited on the basis of the precision and accuracy of available data, sound grasp on the theory and concept behind the mechanism, perception and understanding of the modeling approach, as well as the ability to formulate the internal functions of the process (i.e., forest/stand dynamics).

In reality, forest management is dynamic and primarily an initiative to design a comprehensive planning framework with the essential components to achieve evolving objectives based on vision, policy, and limitations. First of all, management planning can only be executed successfully with a plethora of accurate data and information at the right scale, regularly obtained from the field surveys and readily accessible with advanced technologies such as remote sensing and GIS. Second, up-to-date spatial databases covering the details of landscape structure and the knowledge base from the experts and traditions are prerequisites for the successful preparation of forest management plans. Third, developing a rigorous set of management strategies based on a broader/deep understanding of forest dynamics (biological and technological principles) over time and space is an important aspect of successful management planning. Understanding the cause and effect relationship provides fundamental baseline information to manage the forest ecosystems without jeopardizing ecological integrity and foreclosing future management options. Such exercises provide an opportunity for adaptive management to improve the effectiveness of planning on the ground. Finally, planning is ultimately limited to the quality of the ideas and perception of planning experts in association with the key stakeholders. Structured participation with appropriate role playing and sharing of rights and responsibilities help improve the successful integration of the framework components.

\section{Conclusions}

The decision-making process is an essential aspect of forest management planning process, involving multiple ecosystem services, planning approaches, methods and tools, and multiple stakeholders in addition to the vision, intuition, and wisdom of planners. Decision-making is greatly challenged by the need to develop a working framework to incorporate various dimensions of the planning process and balance between utilization and conservation, considering natural disturbances such as forest fire and climate changes. Key dimensions of the planning framework, defined on the basis of the state-of-the-art research, include spatial scale, compositional context, temporal context, decision-making context, and spatial context. Thus, the quality of decision highly depends on the consideration of spatial features, multiple stakeholders, stand level inventory data, and the hierarchical structure of planning at various scales. 
The main components of the planning process were identified and described on the basis of the framework's principle dimensions. The research highlighted the need of a landscape-level perspective and of spatial resolution to integrate multiple ecosystem services, embracing the complexity of multi-stakeholder and scale issues. It strives for the heterogeneous matrix of landscape and multi-functionality with a few values operating at a range of different spatial and temporal scales, deliberately engaging the social system with the natural system through various stakeholder participation forms in decision-making. Spatial resolution is critical in developing on-the-ground plans as many ecosystem services connote spatial features and require an accurate spatial representation of objects. Methods and tools are the key components to help choose appropriate planning options and support the involvement of stakeholders and public participation in hierarchical planning processes to prepare an efficient plan. They enable the test of theoretical visions or hypotheses before implementing them on the ground and understand future forest dynamics by virtually exercising various planning options. They encapsulate the ecological-economic-social complexity of forest ecosystem management, information about trade-offs between ecosystem services, as well as the sensitivity of the plan to uncertain parameters in a timely manner. Critical aspects of a comprehensive DSS include generality, user-friendliness, transparency, simplification, abstraction, and functionality, besides considering the spatial features of planning problem. It is then only possible to realize an adoptive management approach through circular linking of the theoretical thoughts to the results of management interventions in reality on the ground through decision-making tools.

On the basis of the analysis of related reviews in forest management planning by prominent researchers, we envisage a few emerging challenges of forest management planning that scientists and specifically foresters face today and likely in the future. Acquisition of high-resolution forest inventory data, effective handing of a large spatial database, quantification of all ecosystem services, developing hybrid decision-making tools, having three-dimensional animated management planning in a virtual environment, accommodating risks and uncertainties, having conflict resolution exercises with multiple stakeholders in a virtual environment, integrating management of various land uses in a holistic management concept, forecasting and integrating the effects of climate change on forest landscape dynamics, and using fast computing opportunities with mega computers using parallel processing features are the prevailing challenges in ecosystem management. An adaptive management approach considering integration of stochastic events such as forest fires and pests into the planning process may also contribute to the holistic management of ecosystems. A behavioral model is also an emerging challenge to abstract the socio-economic features of a forest management problem. A mixture of management regimes and silvicultural operations such as two-stage harvesting and large-scale shelter-wood system other than clear-cut are necessary both to help achieve and balance multiple, often conflicting objectives in ecosystem management.

Author Contributions: Conceptualization, E.Z.B. and J.G.B.; writing-original draft, E.Z.B.; writing-review and editing, E.Z.B., J.G.B., J.K., and M.T. All authors have read and agreed to the published version of the manuscript.

Funding: This work received support of the Centro de Estudos Florestais, a research unit funded by Fundação para a Ciência e a Tecnologia I.P. (FCT), Portugal (UIDB/00239/2020) and of the BIOECOSYS project, "Forest ecosystem management decision-making methods: an integrated bioeconomic approach to sustainability" (LISBOA-01-0145-FEDER-030391, PTDC/ASP-SIL/30391/2017). This paper was also supported by the EVA4.0 project, "Advanced Research Supporting the Forestry and Wood-processing Sector's Adaptation to Global Change and the 4th Industrial Revolution" (CZ.02.1.01/0.0/0.0/16_019/0000803) in the Czech University of Life Sciences, Prague.

Conflicts of Interest: The authors declare no conflict of interest.

\section{References}

1. Baskent, E.Z. A review of the development of the multiple use forest management planning concept. Int. For. Rev. 2018, 20, 296-313. [CrossRef]

2. Bettinger, P.; Chung, W. The key literature of and trends in forest-level management planning in North America, 1950-2001. Int. For. Rev. 2004, 6, 40-50. [CrossRef] 
3. Kangas, J.; Kangas, A. Multiple criteria decision support in forest management—-the approach, methods applied, and experiences gained. For. Ecol. Manag. 2005, 207, 133-143. [CrossRef]

4. Pukkala, T.; Kurttila, M. Examining the performance of six heuristic optimization techniques in different forest planning problems. Silva Fenn. 2005, 39, 67-80. [CrossRef]

5. Diaz-Balteiro, L.; Romero, C. Making forestry decisions with multiple criteria: A review and an assessment. For. Ecol. Manag. 2008, 255, 3222-3241. [CrossRef]

6. Ananda, J.; Herath, G. A critical review of multi-criteria decision making methods with special reference to forest management and planning. Ecol. Econ. 2009, 68, 2535-2548. [CrossRef]

7. Hartl, F.H.; Barka, I.; Hahn, W.A.; Hlasny, T.; Irauschek, F.; Knoke, T.; Lexer, M.J.; Griess, V.C. Multifunctionality in European mountain forests-an optimization under changing climatic conditions. Can. J. For. Res. 2016, $46,163-171$.

8. Borges, J.G.; Nordström, E.M.; Garcia-Gonzalo, J.; Hujala, T.; Trasobares, A. Computer-based tools for supporting forest management. In The Experience and the Expertise World-Wide; Department of Forest Resource Management, Swedish University of Agricultural Sciences: Umeå, Sweden, 2014; p. 503.

9. Borges, J.G.; Marques, S.; Garcia-Gonzalo, J.; Rahman, A.U.; Bushenkov, V.; Sottomayor, M.; Carvalho, P.O.; Nordstrom, E.M. A Multiple Criteria Approach for Negotiating Ecosystem Services Supply Targets and Forest Owners' Programs. For. Sci. 2017, 63, 49-61. [CrossRef]

10. Ezquerro, M.; Pardos, M.; Diaz-Balteiro, L. Operational Research Techniques Used for Addressing Biodiversity Objectives into Forest Management: An Overview. Forests 2016, 7, 229. [CrossRef]

11. Baskent, E.Z.; Jordan, G.A. Forest landscape (ecosystems) management with simulated annealing. For. Ecol. Manag. 2002, 165, 29-45. [CrossRef]

12. Shan, Y.; Bettinger, P.; Cieszewski, C.; Li, R.F. Trends in Spatial Forest Planning. Int. J. Math. Comp. Sci. 2009, 1, 86-112.

13. Llorente, I.D.P.; Hoganson, H.M.; Carson, M.T. Recognizing Spatial Considerations in Forest Management Planning. Curr. For. Rep. 2017, 3, 308-316.

14. Mendoza, G.A.; Martins, H. Multi-criteria decision analysis in natural resource management: A critical review of methods and new modelling paradigms. For. Ecol. Manag. 2006, 230, 1-22. [CrossRef]

15. Kangas, A.; Laukkanen, S.; Kangas, J. Social choice theory and its applications in sustainable forest management-A review. For. Policy Econ. 2016, 9, 77-92. [CrossRef]

16. Fischer, A.P. Forest landscapes as social-ecological systems and implications for management. Landsc. Urban Plan. 2018, 177, 138-147. [CrossRef]

17. Bettinger, P.; Sessions, J. Spatial forest planning: To adopt, or not to adopt? J. For. 2003, 101, $24-29$.

18. Borges, J.G.; Hoganson, H.M.; Rose, D.W. Combining a decomposition strategy with dynamic programming to solve spatially constrained forest management scheduling problems. For. Sci. 1999, 45, 201-212.

19. Falcão, A.O.; Borges, J.G. Combining random and systematic search heuristic procedures for solving spatially constrained forest management scheduling problems. For. Sci. 2002, 48, 608-621.

20. McDill, M.E.; Rebain, S.A.; Braze, J. Harvest scheduling with area-based adjacency constraints. For. Sci. 2002, $48,631-642$.

21. Ohman, K.; Lamas, T. Clustering of harvest activities in multi-objective long-term forest planning. For. Ecol. Manag. 2003, 176, 161-171. [CrossRef]

22. Constantino, M.; Martins, I.; Borges, J.G. A new mixed integer programming model for harvest scheduling subject to maximum area restrictions. Oper. Res. 2008, 56, 542-551. [CrossRef]

23. Tóth, S.F.; Könnyú, N.; McDill, M.E.; George, S. Lazy Constraints for Area-Based Adjacency Formulations in Harvest Scheduling Models. For. Sci. 2013, 59, 157-176. [CrossRef]

24. Marušák, R.; Kašpar, J.; Hlavatý, R. Alternative Modelling Approach to Spatial Harvest Scheduling with Respect to Fragmentation of Forest Ecosystem. Environ. Manag. 2015, 56, 1134-1147. [CrossRef]

25. Martins, H.; Borges, J.G. Addressing collaborative planning methods and tools in forest management. For. Ecol. Manag. 2007, 248, 107-118. [CrossRef]

26. Nordström, E.M.; Eriksson, L.O.; Öhman, K. Integrating multiple criteria decision analysis in participatory forest planning: Experience from a case study in northern Sweden. For. Policy Econ. 2010, 12, 562-574. [CrossRef]

27. Ortiz-Urbina, E.; González-Pachón, J.; Diaz-Balteiro, L. Decision-Making in Forestry: A review of the hybridization of multiple criteria and group decision-making techniques. Forests 2019, 10, 375. [CrossRef] 
28. Hujala, T.; Khadka, C.; Wolfslehner, B.; Vacik, H. Supporting problem structuring with computer-based tools in participatory forest planning. For. Syst. 2013, 22, 270-281. [CrossRef]

29. Kangas, J. An Approach to Public-Participation in Strategic Forest Management Planning. For. Ecol. Manag. 1994, 70, 75-88. [CrossRef]

30. Kajanus, M.; Leskinen, P.; Kurttila, M.; Kangas, J. Making use of MCDS methods in SWOT analysis-Lessons learnt in strategic natural resources management. For. Policy Econ. 2012, 20, 1-9. [CrossRef]

31. Marques, S.; Marto, M.; Bushenkov, V.A.; McDill, M.E.; Borges, J.G. Addressing Wildfire Risk in Forest Management Planning with Multiple Criteria Decision Making Methods. Sustainability 2017, 9, 298. [CrossRef]

32. Tóth, S.F.; McDill, M.E. Finding Efficient Harvest Schedules under Three Conflicting Objectives. For. Sci. 2009, 55, 117-131.

33. Tóth, S.F.; McDill, M.E.; Rebain, S. Finding the efficient frontier of a bi-criteria, spatially explicit, harvest scheduling problem. For. Sci. 2007, 52, 93-107.

34. Krott, M.; Bader, A.; Devkota, R.; Maryudi, A.; Giessen, L.; Aurenhammer, H. Actor-centered power: The driving force in decentralized community based forest governance. For. Policy Econ. 2014, 49, $34-42$. [CrossRef]

35. Marques, M.; Juerges, N.; Borges, J.G. Appraisal framework for actor interest and power analysis in forest management-Insights from Northern Portugal. For. Policy Econ. 2020, 111, 102049. [CrossRef]

36. Baskent, E.Z. A Framework for Characterizing and Regulating Ecosystem Services in a Management Planning Context. Forests 2020, 11, 102. [CrossRef]

37. TEEB. The Economics of Ecosystems and Biodiversity: Ecological and Economic Foundations; Kumar, P., Ed.; Earthscan: London, UK; Washington, DC, USA, 2010.

38. MEA. A report of the millennium ecosystem assessment. In Ecosystems and Human Wellbeing: Synthesis; Island Press: Washington, DC, USA, 2005.

39. Haines-Young, R.; Potschin, M.B. Common International Classification of Ecosystem Services (CICES) V5.1 and Guidance on the Application of the Revised Structure. 2018. Available online: http://www.cices.eu (accessed on 1 April 2020).

40. Costanza, R.; de Groot, R.; Braat, L.; Kubiszewski, I.; Fioramonti, L.; Sutton, P.; Farber, S.; Grasso, M. Twenty years of ecosystem services: How far have we come and how far do we still need to go? Ecosyst. Serv. 2017, 28, 1-16. [CrossRef]

41. Edwards, D.; Jensen, F.S.; Marzano, M.; Mason, B.; Pizzirani, S.; Schelhaas, M.J. A theoretical framework to assess the impacts of forest management on the recreational value of European forests. Ecol. Indic. 2011, 11, 81-89. [CrossRef]

42. Eriksson, S.; Hammer, M. The challenge of combining timber production and biodiversity conservation for long-term ecosystem functioning-A case study of Swedish boreal forestry. For. Ecol. Manag. 2006, 237, 208-217. [CrossRef]

43. Gunn, E. Sustainable forest management: Control, adaptive management, hierarchical planning. In Systems Analysis in Forest Resources, Proceedings of the 2003 Symposium, Stevenson, DC, USA, 7-9 October 2003; General Technical Report PNW-GTR-656; Forest Service, Pacific Northwest Research Station; USDA: Portland, OR, USA, 2003; pp. 7-14.

44. Gadow, K.V.; Kurttila, M.; Leskinen, P.; Leskinen, L.; Nuutinen, T. Designing forested landscapes to provide multiple services. In CAB Reviews: Perspectives in Agriculture, Veterinary Science, Nutrition and Natural Resources; CABI Publishing: Wallingford, UK, 2007; Volume 2, 16p, ISSN 1749-8848.

45. Yousefpour, R.; Temperli, C.; Jacobsen, J.B.; Thorsen, B.J.; Meilby, H.; Lexer, M.J.; Lindner, M.; Bugmann, H.; Borges, J.G.; Palma, J.H.N.; et al. A framework for modeling adaptive forest management and decision making under climate change. Ecol. Soc. 2017, 22, 40. [CrossRef]

46. Kaspar, J.; Bettinger, P.; Vacik, H.; Marusak, R.; Garcia-Gonzalo, J. Decision Support Approaches in Adaptive Forest Management. Forests 2018, 9, 215. [CrossRef]

47. Borges, J.G.; Hoganson, H.M. Structuring a landscape by forestland classification and harvest scheduling spatial constraints. For. Ecol. Manag. 2000, 130, 269-275. [CrossRef]

48. Yoshimoto, A.; Patrick, A. Focal-Point Aggregation under Area Restrictions through Spatially Constrained Optimal Harvest Scheduling. For. Sci. 2019, 65, 164-177. [CrossRef] 
49. Kaspar, J.; Perez, G.F.E.; Cerveira, A.; Marusak, R. Spatial considerations of an area restriction model for identifying harvest blocks at commercial forest plantations. Cent. Eur. For. J. 2016, 62, 146-151.

50. Karlsson, J.; Ronnqvist, M.; Bergstrom, J. An optimization model for annual harvest planning. Can. J. For. Res. 2004, 34, 1747-1754. [CrossRef]

51. D'Amours, S.; Rönnqvist, M.; Weintraub, A. Using operational research for supply chain planning in the forest products industry. INFOR 2008, 46, 265-282. [CrossRef]

52. Heinonen, T.; Makinen, A.; Rasinmaki, J.; Pukkala, T. Aggregating microsegments into harvest blocks by using spatial optimization and proximity objectives. Can. J. For. Res. 2018, 48, 1184-1193. [CrossRef]

53. Bettinger, P.; Graetz, D.; Boston, K.; Sessions, J.; Chung, W. Eight heuristic planning techniques applied to three increasingly difficult wildlife planning problems. Silva Fenn. 2002, 36, 561-584. [CrossRef]

54. Heinonen, T.; Pukkala, T. The use of cellular automaton approach in forest planning. Can. J. For. Res. 2007, 37, 2188-2200. [CrossRef]

55. Borges, J.G.; Hoganson, H.M.; Falcao, A.O. Heuristics in multi-objective forest management. Multi-Object. For. Plan. Book Ser. Manag. For. Ecosyst. 2002, 6, 119-151.

56. Pukkala, T.; Heinonen, T. Optimizing heuristic search in forest planning. Nonlinear Anal. Real World Appl. 2006, 7, 1284-1297. [CrossRef]

57. Dong, L.; Bettinger, P.; Liu, Z.; Qin, H.; Zhao, Y. Evaluating the neighborhood, hybrid and reversion search techniques of a simulated annealing algorithm in solving forest spatial harvest scheduling problems. Silva Fennica 2016, 50, 20p. [CrossRef]

58. Bettinger, P.; Boston, K. Forest Planning Heuristics-Current Recommendations and Research Opportunities for s-Metaheuristics. Forests 2017, 8, 476. [CrossRef]

59. Murray, A.T. Spatial restrictions in harvest scheduling. For. Sci. 1999, 45, 45-52.

60. Boston, K.; Bettinger, P. Combining tabu search and genetic algorithm heuristic techniques to solve spatial harvest scheduling problems. For. Sci. 2002, 48, 35-46.

61. Goycoolea, M.A.; Murray, T.; Vielma, J.P.; Weintraub, A. Evaluating alternative approaches for solving the area restriction model in harvest scheduling. For. Sci. 2009, 55, 149-165.

62. Könnyú, N.; Tóth, S.F.; McDill, M.E.; Rajasekaran, B. Temporal Connectivity of Mature Patches in Forest Planning Models. For. Sci. 2014, 60, 1089-1099. [CrossRef]

63. Moreira, F.; Viedma, O.; Arianoutsou, M.; Curt, K.; Koutsias, N.; Rigolot, E.; Barbati, A.; Corona, P.; Vaz, P.; Xanthopoulos, G.; et al. Landscape-wildfire interactions in southern Europe: Implications for landscape management. J. Environ. Manag. 2011, 92, 2389-2402. [CrossRef]

64. Navalho, I.; Alegria, C.; Roque, N.; Quinta-Nova, L. Mapping Forest Landscape Multifunctionality Using Multicriteria Spatial Analysis. Floresta E Ambiente 2019, 26, e20170702. [CrossRef]

65. Pasqualini, V.; Oberti, P.; Vigetta, S.; Riffard, O.; Otis, C.P.; Cannac, M.; Ferrat, L. A GIS-Based Multicriteria Evaluation for Aiding Risk Management Pinus pinaster Ait. Forests: A Case Study in Corsican Island, Western Mediterranean Region. Environ. Manag. 2011, 48, 38-56. [CrossRef]

66. Eskandari, S. A new approach for forest fire risk modeling using fuzzy AHP and GIS in Hyrcanian forests of Iran. Arab. J. Geosci. 2017, 10,1-13. [CrossRef]

67. Goleiji, E.; Hosseini, S.M.; Khorasani, N.; Monavari, S.M. Forest fire risk assessment-an integrated approach based on multicriteria evaluation. Environ. Monit. Assess. 2017, 189, 612. [CrossRef]

68. Mirchi, A.; Watkins, D.; Madani, K. Modeling for watershed planning, management and decision making, Chapter 6. In Watersheds: Management, Restoration and Environmental; Vaughn, J.C., Ed.; Nova Science Publications, Inc.: Hauppauge, NY, USA, 2009; ISBN 978-1-61668-667-3.

69. Gimenez, J.C.; Diaz-Balteiro, L.; Bertomeu, M. The effective hydrological neighborhood: A new concept to formulate harvest area constraints. Ecol. Model. 2019, 404, 83-90. [CrossRef]

70. Baskent, E.Z.; Keles, S. Spatial forest planning: A review. Ecol. Model. 2005, 188, 145-173. [CrossRef]

71. Janeczko, E. Formal and legal aspects of the forest landscape planning. Sylwan 2012, 156, 463-472.

72. Nilsson, H.; Nordstrom, E.M.; Ohman, K. Decision Support for Participatory Forest Planning Using AHP and TOPSIS. Forests 2016, 7, 100. [CrossRef]

73. Marques, S.; Bushenkov, V.A.; Lotov, A.V.; Marto, M.; Borges, J.G. Bi-Level Participatory Forest Management Planning Supported by Pareto Frontier Visualization. For. Sci. 2020, 66, 490-500. [CrossRef] 
74. Reynolds, K.M.; Borges, J.G.; Vacik, H.; Lexer, M.J. Information and communication technology in forest management and conservation. In Information Technology and the Forest Sector; Hetemaki, L., Nilsson, S., Eds.; IUFRO World Series Volume 18; International Union of Forest Research Organizations: Vienna, Austria, 2005; pp. 150-171.

75. Pukkala, T. Which type of forest management provides most ecosystem services? For. Ecosyst. 2016,3 , 9. [CrossRef]

76. Bugmann, H.; Palahi, M.; Bontemps, H.D.; Tomé, M. Trends in modeling to address forest management and environmental challenges in Europe: Introduction. For. Syst. 2010, 19, 3-7. [CrossRef]

77. Calama, R.; Tome, M.; Sánchez-González, M.; Miina, J.; Spanos, K.; Palahi, M. Modelling Non-Wood Forest Products in Europe: A review. For. Syst. 2010, 19, 69-85. [CrossRef]

78. Botequim, B.; Arias-Rodil, M.; Garcia-Gonzalo, M.; Silva, A.; Marques, S.; Borges, J.G.; Oliveira, M.M.; Tomé, M. Modelling post-fire mortality in pure and mixed forest stands in Portugal-A forest planning-oriented model. Sustainability 2017, 9, 390. [CrossRef]

79. Rodrigues, A.R.M.; Botequim, B.; Tavares, C.; Pécurto, P.; Borges, J.G. Addressing soil protection concerns in forest ecosystem management under climate change. For. Ecosyst. 2020, 7, 34. [CrossRef]

80. Aldea, J.; Martínez-Peña, F.; Romero, C.; Diaz-Balteiro, L. Participatory Goal Programming in Forest Management: An Application Integrating Several Ecosystem Services. Forests 2014, 5, 3352-3371. [CrossRef]

81. Lohmander, P. Optimal sequential forestry decisions under risk. Ann. Oper. Res. 2000, 95, 217-228. [CrossRef]

82. Kabli, M.R.; Gan, J.; Ntaimo, L. A Stochastic Programming Model for Fuel Treatment Management. Forests 2015, 6, 2148-2162. [CrossRef]

83. Borges, J.G.; Garcia-Gonzalo, J.; Bushenkov, V.; McDill, M.E.; Marques, S.; Oliveira, M.M. Addressing Multi-criteria Forest Management with Pareto Frontier Methods: An Application in Portugal. For. Sci. 2014, 60, 63-72. [CrossRef]

84. Mallach, E.G. Understanding Decision Support Systems and Expert Systems; Richard d Irwin Publishing: Huntsville, NC, USA, 1993; 695p, ISBN 13 978-0256118964.

85. Reynolds, K.M.; Rodriguez, S.; Bevans, K. User guide for the Ecosystem Management Decision Support System, Version 3.0; Environmental Systems Research Institute: Redlands, CA, USA, 2003.

86. Garcia-Gonzalo, J.; Borges, J.G. Models and tools for integrated forest management and forest policy analysis: An Editorial. For. Policy Econ. 2019, 103, 1-3. [CrossRef]

87. Reynolds, K.M.; Twery, M.; Lexer, M.J.; Vacik, H.; Ray, D.; Shao, G.; Borges, J.G. Decision Support Systems in Forest Management. In Handbook on Decision Support Systems 2; Burstein, F., Holsapple, C., Eds.; Springer: Berlin/Heidelberg, Germany, 2008; Volume 2, pp. 499-533. ISBN 978-3-540-48716-6.

88. Pyatt, D.G.; Ray, D.; Fletcher, J. An Ecological Site Classification for Forestry in Great Britain; Forestry Commission Bulletin 124; Forestry Commission: Edinburgh, UK, 2001.

89. Borges, J.G.; Falcão, A.; Miragaia, C.; Marques, P.; Marques, M. A decision support system for forest resources management in Portugal. In System Analysis in Forest Resources, Managing Forest Ecosystems; Arthaud, G.J., Barrett, T.M., Eds.; Kluwer Academic Publishers: Dordrecht, The Netherlands, 2003; Volume 7, pp. 155-164.

90. Gardiner, B.A.; Suarez, J.; Quine, J.P. Development of a GIS based wind risk system for British forestry. In Wind Effects on Trees, Proceedings of International Conference, 16-18 September 2003; Ruck, B., Kottmeier, C., Mattheck, C., Quine, C., Wilhelm, G., Eds.; University of Karlsruhe: Karlsruhe, Germany, 2003; pp. 145-150. ISBN 3-00-011922-1.

91. Garcia-Quijano, J.J.; Deckmyn, G.; Moons, E.; Proost, S.; Ceulemans, R.; Muys, B. An integrated decision support framework for the prediction and evaluation of efficiency, environmental impact and total social cost of domestic and international forestry projects for greenhouse gas mitigation: Description and case studies. For. Ecol. Manag. 2005, 207, 245-262. [CrossRef]

92. Lexer, M.J.; Vacik, H.; Palmetzhofer, D.; Oitzinger, G. A decision support tool to improve forestry extension services for small private landowners in southern Austria. Comput. Electron. Agric. 2005, 49, 81-102. [CrossRef]

93. Shao, G.; Wang, H.; Dai, L.; Wu, G.; Li, Y.; Lang, R.; Song, B. Integrating stand and landscape decisions for multi-purposes of forest harvesting. For. Ecol. Manag. 2005, 207, 233-243. [CrossRef]

94. Twery, M.J.; Knopp, P.D.; Thomasma, S.A.; Rauscher, H.M.; Nute, D.E.; Potter, W.D.; Maier, F.; Wang, J.; Dass, M.; Uchiyama, H.; et al. NED-2: A decision support system for integrated forest ecosystem management. Comput. Electron. Agric. 2005, 49, 24-43. [CrossRef] 
95. Remsoft. About the Remsoft spatial planning system. In Allocation Optimizer User Guide; Remsoft Inc.: Fredericton, NB, Canada, 2005; pp. 9-14.

96. Vacik, H.; Lexer, M.J. Past, current and future drivers for the development of decision support systems in forest management. Scand. J. For. Res. 2014, 29, 2-19. [CrossRef]

97. Marto, M.; Reynolds, K.M.; Borges, J.G.; Bushenkov, V.A.; Marques, S. Combining Decision Support Approaches for Optimizing the Selection of Bundles of Ecosystem Services. Forests 2018, 9, 438. [CrossRef]

98. Marto, M.; Reynolds, K.M.; Borges, J.G.; Bushenkov, V.A.; Marques, S.; Marques, M.; Barreiro, S.; Botequim, B.; Tomé, M. Web-Based Forest Resources Management Decision Support System. Forests 2019, 10, 1079. [CrossRef]

99. Rammer, W.; Schauflinger, C.; Vacik, H.; Palma, J.H.N.; Garcia-Gonzalo, J.; Borges, J.G.; Lexer, M.J. A web-based ToolBox approach to support adaptive forest management under climate change. Scand. J. For. Res. 2014, 29, 96-107. [CrossRef]

100. Nordström, E.M.; Nieuwenhuis, M.; Baskent, E.Z.; Biber, P.; Black, K.; Borges, J.G.; Bugalho, M.N.; Corradini, G.; Corrigan, E.; Eriksson, O. Forest decision support systems for the analysis of ecosystem services provisioning at the landscape scale under global climate and market change scenarios. Eur. J. For. Res. 2019, 138, 561-581. [CrossRef]

101. Vacik, H.; Borges, J.G.; Kašpar, J. Challenges in the design of Forest Management Decision Support Systems addressing sustainability and societal demands. In ICDSST 2016, Proceedings of the Ewg-dss 2016 INT. Conference on Decision Support System Technology: Decision Support Systems Addressing Sustainability E Societal Challenges, Plymouth, UK, 23-25 May 2016; Liu, S., Delibašić, B., Linden, I., Oderanti, F., Eds.; Springer International Publishing AG: Cham, Switzerland, 2016; Volume XVI, 217p.

102. Marques, A.; Borges, J.G.; Sousa, P.; Pinho, A.M. An enterprise architecture approach to forest management decision support design. An application to pulpwood supply management in Portugal. Eur. J. For. Res. 2011, 30, 935-948. [CrossRef]

103. Pastorella, F.; Borges, J.G.; De Meo, I. Usefulness and Perceived Usefulness of Decision Support Systems (DSSs) in participatory forest planning: The final users' point of view. Iforest-Biogeosci. For. 2016, 9, 422-429. [CrossRef]

104. Michael, D.R.; Chen, S.L. Serious Games: Games That Edu-Cate, Train, and Inform; Muska \& Lipman/Premier-Trade: Dubai, UAE, 2005; 312p, ISBN 978-1-59200-622-9.

105. Laamarti, F.; Eid, M.; El Saddik, A. An Overview of Serious Games. Int. J. Comput. Games Technol. 2014, 358152. [CrossRef]

106. Rodela, R.; Ligtenberg, A.; Bosma, R. Conceptualizing Serious Games as a Learning-Based Intervention in the Context of Natural Resources and Environmental Governance. Water 2019, 11, 245. [CrossRef]

107. Arts, B.; Visseren-Hamakers, I.J. Forest Governance: A State of the Art Review. In Forest-People Interfaces; Arts, B., van Bommel, S., Ros-Tonen, M., Verschoor, G., Eds.; Wageningen Academic Publishers: Wageningen, The Netherlands, 2012; pp. 241-259.

108. McGinley, K.; Alvarado, R.; Cubbage, F.; Diaz, D.; Donoso, P.J.; Jacovine, L.A.G.; de Silva, F.L.; MacIntyre, C.; Zalazar, E.M. Regulating the Sustainability of Forest Management in the Americas: Cross-Country Comparisons of Forest Legislation. Forests 2012, 3, 467-505. [CrossRef]

109. Vacik, H.; Borges, J.G.; Garcia-Gonzalo, J.; Eriksson, O. Decision Support for the Provision of Ecosystem Services under Climate Change: An Editorial. Forests 2015, 6, 3212-3217. [CrossRef]

110. Duncker, P.S.; Barreiro, S.M.; Hengeveld, G.M.; Lind, T.; Mason, W.L.; Ambrozy, S.; Spiecker, H. Classification of forest management approaches: A new conceptual framework and its applicability to European forestry. Ecol. Soc. 2012, 17, 51. [CrossRef]

111. Nyongesa, K.W.; Vacik, H. Evaluating Management Strategies for Mount Kenya Forest Reserve and National Park to Reduce Fire Danger and Address Interests of Various Stakeholders. Forests 2019, 10, 426. [CrossRef]

112. Lodin, I.; Eriksson, L.O.; Forsell, N.; Korosuo, A. Combining Climate Change Mitigation Scenarios with Current Forest Owner Behavior: A Scenario Study from a Region in Southern Sweden. Forests 2020, 11, 346. [CrossRef]

113. Benz, J.; Chen, S.; Dang, S.; Dieter, M.; Labelle, E.R.; Liu, G.; Hou, L.; Mosandl, R.M.; Pretzsch, H.; Pukall, K.; et al. Multifunctionality of Forests: A White Paper on Challenges and Opportunities in China and Germany. Forests 2020, 11, 266. [CrossRef] 
114. Bauhus, J.; Puettmann, K.; Kühne, C. Close-to-Nature Forest Management in Europe: Does It Support Complexity and Adaptability of Forest Ecosystems. In Managing Forests as Complex Adaptive Systems: Building Resilience to the Challenge of Global Change; Messier, C., Puettmann, K.J., Coates, K.D., Eds.; The Earthscan forest library; Routledge Publishing: Abington, UK, 2013; pp. 187-213.

115. Boncina, A. Conceptual approaches to integrate nature conservation into forest management: A Central European perspective. Int. For. Rev. 2011, 13, 13-22.

116. Orazio, C.; Cordero Montoya, R.; Régolini, M.; Borges, J.G.; Garcia-Gonzalo, J.; Barreiro, S.; Botequim, B.; Marques, S.; Sedmák, R.; Brodrechtová, Y.; et al. Review: Decision Support Tools and Strategies to Simulate Forest Landscape Evolutions Integrating Forest Owner Behavior: A Review from the Case Studies of the European Project, INTEGRAL. Sustainability 2017, 9, 599. [CrossRef]

117. Barreiro, S.; Rua, J.; Tome, M. StandsSIM-MD: A Management Driven forest SIMulator. For. Syst. $2016,25$. [CrossRef]

118. Merganic, J.; Merganicová, K.; Výbošt'ok, J.; Valent, P.; Bahýl', J.; Yousefpour, R. Searching for Pareto Fronts for Forest Stand Wind Stability by Incorporating Timber and Biodiversity Values. Forests 2020, 11, 583. [CrossRef]

119. Kaya, A.; Bettinger, P.; Boston, K.; Akbulut, R.; Ucar, Z.; Siry, J.; Merry, K.; Cieszewski, C. Optimisation in Forest Management. Curr. For. Rep. 2016, 2, 1-17. [CrossRef]

120. Belavenutti, P.; Romero, C.; Diaz-Balteiro, L. Integrating Strategic and Tactical Forest-Management Models within a Multicriteria Context. For. Sci. 2019, 65, 178-188. [CrossRef]

121. Eyvindson, K.; Rasinmäki, J.; Kangas, A. Evaluating a hierarchical approach to landscape level harvest scheduling. Can. J. For. Res. 2018, 48, 208-215. [CrossRef]

122. Balint, P.J.; Stewart, R.E.; Desai, A.; Walters, L.C. Wicked Environmental Problems: Managing Uncertainty and Conflict; Island Press: Washington, DC, USA, 2011.

123. Reed, J.; Barlow, J.; Carmenta, R.; van Vianen, J.; Sunderland, T. Engaging multiple stakeholders to reconcile climate, conservation and development objectives in tropical landscapes. Biol. Conserv. 2019, 238, 108229. [CrossRef]

124. Running, S.W.; Coughlan, J.C. A general-model of forest ecosystem processes for regional applications 1. Hydrologic balance, canopy gas-exchange and primary production processes. Ecol. Model. 1988, 42, 125-154. [CrossRef]

125. Mäkelä, A.; Mäkinen, H. Generating 3D sawlogs with a process-based growth model. For. Ecol. Manag. 2003, 184, 337-354. [CrossRef]

126. Hailian, X.; Mäkelä, A.; Valsta, L.; Vanclay, J.K.; Cao, T. Comparison of population-based algorithms for optimizing thinnings and rotation using a process-based growth model. Scand. J. For. Res. 2019, 34, 458-468.

127. Mina, M.; Bugmann, H.; Cordonnier, T.; Irauschek, F.; Klopcic, M.; Pardos, M.; Cailleret, M. Future ecosystem services from European mountain forests under climate change. J. Appl. Ecol. 2017, 54, 389-401. [CrossRef]

128. Bravo, F.; Fabrika, M.; Ammer, C.; Barreiro, S.; Bielak, K.; Coll, L.; Fonseca, T.; Kangur, A.; Lof, M.; Merganicova, K.; et al. Modelling approaches for mixed forests dynamics prognosis. Research gaps and opportunities. For. Syst. 2019, 28, eR002. [CrossRef]

129. Horemans, J.A.; Joanna, A.; Henrot, A.; Delire, C.; Kollas, C.; Lasch-Born, P.; Reyer, C.; Suckow, F.; Francois, L.; Ceulemans, R. Combining multiple statistical methods to evaluate the performance of process-based vegetation models across three forest stands. Cent. Eur. For. J. 2017, 63, 153-172. [CrossRef]

130. Pretzsch, H. Density and growth of forest stands revisited. Effect of the temporal scale of observation, site quality, and thinning. For. Ecol. Manag. 2020, 460, 117879. [CrossRef]

Publisher's Note: MDPI stays neutral with regard to jurisdictional claims in published maps and institutional affiliations.

(C) 2020 by the authors. Licensee MDPI, Basel, Switzerland. This article is an open access article distributed under the terms and conditions of the Creative Commons Attribution (CC BY) license (http://creativecommons.org/licenses/by/4.0/). 